\title{
PENGELOLAAN ZAKAT DALAM PENGENTASAN KEMISKINAN
}

\author{
Irma khaerunnisa \\ Program Studi Ekonomi Syariah STAI Al-Azhar Gowa \\ Irmakhaerunnisa607@gmail.com
}

\begin{abstract}
Abstrak : Zakat merupakan bagian dari program pengembangan dana sosial syariah, yang memiliki dampak langsung terhadap kehidupan sosial dan ekonomi masyarakat. Dalam Islam upaya pengatasan kemiskinan adalah dengan zakat. Oleh karena itu, zakat seharusnya dikelola secara produktif dan profesional sehingga zakat dapat mengambil bagian dalam merealisasikan ide-ide Islam untuk mensejahterakan masyarakat.
\end{abstract}

Kata kunci : Zakat,Kemiskinan,Pengelolaam dan Pengentasan

\begin{abstract}
Zakat, is part of the sharia social fund development program, which has a direct impact on the social and economic life of the community. In Islam, poverty alleviation efforts are through zakat. Therefore, zakat should be managed productively and professionally so that zakat can take part in realizing Islamic ideas for the welfare of society.
\end{abstract}

Keyword : : Zakat, Poverty, Management and Alleviation

\section{Pendahuluan}

Kemiskinan merupakan bahaya besar bagi umat manusia, tidak sedikit umat yang jatuh peradabannya hanya karena kefakiran. Karena itu seperti sabda Nabi yang menyatakan bahwa kefakiran itu mendekati pada kekufuran. Agama Islam telah menawarkan beberapa doktrin bagi manusia yang universal dengan dua ciri dimensi, yaitu kebahagiaan dan kesejahteraan hidup di dunia dan akhirat.

Zakat merupakan salah satu dari rukun islam dan lima nilai instrumental pengentas kemiskinan yang strategis dan berpengaruh pada tingkah laku ekonomi masyarakat sehingga tujuan zakat tidak hanya menyantuni secara konsumtif namun juga memiliki tujuan permanen untuk mengentaskan kemiskinan.

Tujuan zakat baru dapat dipahami dan diyakini apabila di dalam jiwa seseorang telah tumbuh beberapa nilai, seperti keamanan, kemanusian dan keadilan. Oleh karena itu, Al-Qur'an menggunakan kata sedekah sebagai pedoman dari kata zakat tersebut, karena makna sedekah itu sendiri merupakan manisfestasi atas penguat dan pembenaran yang melahirkan keyakinan, sehingga timbul kesadaran untuk memberikan sebagian dari harta yang disayangi itu dalam bentuk zakat. Hal itu dipandang logis dan wajar bahkan merupakan keharusan. Sebagai sarana pendistribusian harta salah satunya 
adalah zakat. Dengan zakat harta yang padanya terdapat harta hak orang-orang lain yang harus diberikan, sebagai penyucian dari harta tersebut.

Zakat juga dapat dikembangkan menjadi suatu usaha atau program yang produktif dan bisa menghasilkan keuntungan, maka dapat membantu mengentaskan kemiskinan di negeri serta menciptakan kesejahteraan dan keadilan bagi seluruh rakyatnya. ${ }^{1}$

\section{Pembahasan}

A. Pengertian Zakat

Zakat berasal dari bentukan kata zaka yang berarti 'suci', 'baik', 'berkah', 'tumbuh', dan 'berkembang'.Senada dengan Yusuf Qardhawi bahwa kata dasar zaka berarti bertambah dan tumbuh, sehingga bisa dikatakan bahwa "tanaman itu zaka", artinya tanaman itu tumbuh. Menurut terminologi syariat (istilah), zakat adalah nama bagi sejumlah harta tertentu yang diwajibkan oleh Allah untuk dikeluarkan zakat dan diberikan kepada yang berhak menerimanya dengan persyaratan tertentu pula. Kaitan antara makna secara bahasa dan istilah ini berkaitan erat sekali, yaitu bahwa setiap harta yang sudah dikeluarkan zakatnya akan menjadi suci, bersih, baik, berkah tumbuh, dan berkembang (at-Taubah: 103 dan Ar-Rum: 39). ${ }^{2}$

Zakat dalam istilah fiqih berarti sejumlah harta tertentu yang diwajibkan Allah SWT diserahkan kepada orang-orang yang berhak. Pengertian secara syara' zakat mempunyai banyak arti, diantaranya:

1. Menurut Yusuf Qardhawi, zakat adalah sejumlah harta tertentu yang diwajibkan oleh Allah SWT dan diserahkan pada orang-orang yang berhak.

2. Abdur Rahman al-Jazari berpendapat bahwa zakat adalah penyerahan kepemilikan kepada orang yang berhak menerimanya dengan syarat-syarat tertentu pula.

3. Muhammad al-Jurjani, mendefinisikan zakat sebagai kewajiban yang telah ditentukan oleh Allah SWT bagi orang-orang Islam untuk mengeluarkan sejumlah harta yang dimiliki. $^{3}$

B. Tujuan Zakat

\footnotetext{
${ }^{1}$ Rldwan Triandi Abdullah, Dadang Kuswana, and Yuliani Yuliani, "Pola Pengelolaan Manajemen Zakat BAZ Kota Bandung Dalam Mengatasi Kemiskinan," Tadbir: Jurnal Manajemen Dakwah 1, no. 4 (2016): 356, https://doi.org/10.15575/tadbir.v1i4.145.

2 Abd.wahid Trisno, A.syathir, "Maqasid Zakat Dalam Mengentaskan Kemiskinan," Tasamuh;Studi Islam 12 (2020): 359.

${ }^{3}$ Trisno, A.syathir, 360.
} 
Sebagai salah satu rukun Islam, tentu saja zakat mengandung tujuan. Adapun tujuaanya dapat dilihat dari berbagai aspek, antara lain adalah dari aspek ibadah, sosial, dan ekonomi.

1. Tujuan zakat dalam aspek ibadah adalah suatu bentuk penghambaan seorang insan kepada Allah selaku Pencipta, Pemilik, \& Pengatur alam semesta beserta isinya melalui pengorbanan harta. Bagi setiap muslim, pengorbanan ini diwujudkan melalui zakat fitrah (yaitu zakat bagi setiap jiwa yang hidup). Sedangkan bagi setiap individu yang memiliki harta dalam jumlah yang cukup, maka disyariatkan untuk menunaikan zakat maal (zakat harta).

2. Tujuan zakat dalam aspek sosial adalah menjadi media distribusi kekayaan antara orang-orang yang berkelebihan harta dengan orang-orang yang kekurangan harta. Dalam kaitan ini, maka zakat mempunyai dimensi tujuan antara lain adalah:

a. Mengatasi kelaparan dan rasa sakit

b. Mengatasi kesulitan tempat tinggal

c. Menyediakan atau membantu pendidikan masyarakat.

d. Mengatasi kesulitan pada saat darurat atau mendesak (contohnya memenuhi kebutuhan pokok dan kebutuhan dasar manusia lainnya pada saat terjadi bencana).

3. Tujuan zakat dalam aspek ekonomi adalah media sirkulasi kekayaan agar harta tidak berputar di kalangan orang-orang kaya saja. Zakat merupakan wahana distribusi kekayaan, agar komponen masyarakat yang dapat menikmati harta menjadi semakin luas. Zakat adalah instrumen pemerataan pendapatan ekonomi masyarakat pada masyarakat Muslim, agar kesenjangan ekonomi dapat dikurangi melalaui penyampaian zakat kepada orang-orang miskin. ${ }^{4}$

Yusuf Qardawi menguraikan tujuan zakat secara umum mejadi dua, yakni dampaknya bagi si pemberi dan dampaknya bagi si penerima. Adapun dampaknya bagi si pemberi adalah sebagai berikut:

1) Zakat mensucikan jiwa dari sifat kikir

2) Zakat mendidik berinfak dan memberi

3) Berakhlak dengan akhlak Allah

4) Zakat merupakan manifestasi syukur atas nikmat Allah

5) Zakat mengobagi hati dari cinta dunia

6) Zakat mengembangkan kekayaan batin

\footnotetext{
${ }^{4}$ Trisno, A.syathir, 361-62.
} 
7) Zakat menarik rasa simpati/cinta

8) Zakat mensucikan harta kecuali harta yang haram, dan

9) Zakat mengembangkan harta.

Selanjutnya dampak zakat bagi si penerima ada dua yakni membebaskan sipenerima dari kebutuhan dan menghilangkan sifat dengki dan benci.

Secara umum tujuan zakat tersebut di atas di ilhami dari Firman Allah dalam QS. At-Taubah (9): 103 sebagai berikut:

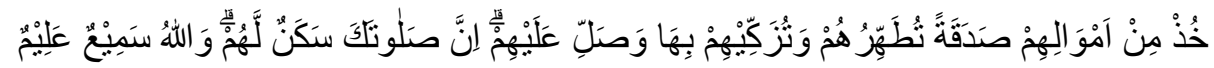

Artinya;

"Ambillah zakat dari sebagian harta mereka, dengan zakat itu kamu membersihkan dan mensucikan mereka dan mendoalah untuk mereka. Sesungguhnya doa kamu itu (menjadi) ketenteraman jiwa bagi mereka. dan Allah Maha mendengar lagi Maha mengetahui."

Ayat tersebut di atas mengisyaratkan bahwa dengan melaksanakan perintah menunaikan zakat akan melahirkan cinta kepada Allah dan cinta kepada sesama manusia, yang sarat dengan kepentingan pribadi dan sosial di dalamnya. Sehingga tersirat di dalamnya tujuan yang bersifat agamis, moral-spriritual, finansial, ekonomis, sosial dan politik, yang pada akhirnya adalah untuk mencapai kemakmuran dan kesejahteraan masyarakat. $^{5}$

Selain fungsi pemerataan, zakat yang dibagikan kepada orang-orang miskin juga difungsikan sebagai modal untuk menciptakan usaha baru, menciptakan lapangan kerja baru, dan menjadi nilai tambah bagi masyarakat dalam mengelola sumber daya alam yang ada sehingga bernilai produktif. Adapun tujuan dalam jangka panjang, zakat juga bertujuan untuk mewujudkan suatu masyarakat yang hidup sejahtera dan mandiri tanpa bergantung pada belas kasihan orang lain atau tanpa harus meminta-minta kepada masyarakat lainnya.

C. Pengertian Kemiskinan

Kemiskinan berasal dari kata سكونا - يسكن - سكن yang berarti mendiami, menenangkan dan menjadi miskin. Kemiskinan juga berarti keadaan melarat atau keadaan miskin. Orang miskin adalah orang yang memiliki harta dan memiliki

\footnotetext{
${ }^{5}$ Samsul, "TUJUAN DAN SASARAN ZAKAT DALAM KONTEKS IBADAH DAN MUAMALAH," IBEF 1 (2020): 85-86.
} 
pekerjaan halal yang sesuai dengannya yang bisa menutupi kebutuhannya dan orang yang berada di bawah tanggung jawabnya, namun sebenarnya tidak mencukupi secara Ideal. Islam menentukan beberapa kebutuhan yang bersifat mendasar dan harus dipenuhi. Kebutuhan itu adalah makanan, pakaian (Q.S Al-Baqarah : 233) dan tempat tinggal (Q.S Ath-Thalaq : 6). Ketiga kebutuhan itulah yang wajib dipenuhi. Selain ketiganya merupakan kebutuhan sekunder. Sedangkan orang kaya menurut para fuqaha adalah orang yang bisa mengusahakan pemenuhan makanan pokoknya berikut keluarganya. Dengan begitu, ia tidak memerlukan lagi makanan yang semisal. Ia juga mampu mengusahakan pakaian dan tempat tinggal mereka, termasuk yang semisalnya kendaraan dan perhiasan secara layak. Jadi, orang kaya adalah orang yang bisa memenuhi kebutuhan-kebutuhannya berikut orang yang menjadi tanggungannya secara layak, bukan hanya kebutuhan pokok tetapi juga kebutuhan lain yang menjadi kebutuhan mereka menurut kelayakan di masyarakat. Kecukupan pemenuhan kebutuhan itu bukan hanya pemenuhan ala kadarnya, tetapi harus secara ma'ruf (Q.S Al- Baqarah : 233). ${ }^{6}$

Menurut UNICEF, kemiskinan sebagai ketidakmilikan hal-hal secara materi kebutuhan minimal manusia termasuk kesehatan, pendidikan dan jasajasa lainnya yang dapat menghindarkan manusia dari kemiskinan. Ravalion menyatakan dalam dekade 1970-an merumuskan garis kemiskinan (poverty line) untuk menetukan tingkat pendapatan minimum yang cukup untuk memenuhi kebutuhan fisik dasar setiap orang berupa kebutuhan makan, pakaian serta perumahan sehingga dapat menjamin kelangsungan hidupnya.

Blank menguraikan konsep tentang karakteristik lokal yang berpotensi mempengaruhi tingkat kemiskinan dan kebijakan yang mempengaruhinya. karakteristik tersebut adalah: lingkungan alamiah, struktur ekonomi, kelembagaan dan karakteristik penduduk suatu daerah local. World Bank menjelaskan beberapa karakteristik penduduk miskin diantaranya: gizi buruk, rendahnya pendidikan, umur harapan hidup dan standar perumahan. Sepuluh tahun kemudian World Bank mengeluarkan laporan tentang memerangi kemiskinan yang menekankan pada karakteristik lain yaitu pada umumnya mereka memiliki kedudukan yang lemah dalam menyuarakan kepentingannya dan rentan terhadap gejolak ekonomi.

\footnotetext{
${ }^{6}$ Trisno, A.syathir, “Maqasid Zakat Dalam Mengentaskan Kemiskinan,” 362-63.
} 
Badan Perencanaan Pembangunan Nasional (Bappenas) menjelaskan kemiskinan adalah situasi serba kekurangan yang terjadi bukan karena dikehendaki oleh si miskin, melainkan karena tidak dapat dihindari dengan kekuatan yang ada padanya. Pendapat lain dikemukakan oleh Ali dalam Setyawan yang menyatakan kemiskinan adalah adanya gap atau jurang antara nilai-nilai utama yang diakumulasikan dengan pemenuhan kebutuhan akan nilai-nilai tersebut secara layak. Menurut Chambers ada lima ketidakberuntungan yang melingkari kehidupan orang miskin yaitu:

(1) Kemiskinan (poverty), memiliki tanda-tanda sebagai berikut: rumah reot dan dibuat dari bahan bangunan yang bermutu rendah, perlengkapan yang sangat minim, ekonomi keluarga ditandai dengan ekonomi gali lubang tutup lubang serta pendapatan yang tidak menentu.

(2) Masalah kerentanan (vulnerability), kerentanan ini dapat dilihat dari ketidakmampuan keluarga miskin menghadapi situasi darurat. Perbaikan ekonomi yang dicapai dengan susah payah sewaktu-waktu dapat lenyap ketika penyakit menghampiri keluarga mereka yang membutuhkan biaya pengobatan dalam jumlah yang besar.

(3) Masalah ketidakberdayaan (powerlessness). Bentuk ketidakberdayaan kelompok miskin tercermin dalam ketidakmampuan mereka dalam menghadapi elit dan para birokrasi dalam menentukan keputusan yang menyangkut nasibnya, tanpa memberi kesempatan untuk mengaktualisasi diri.

(4) Lemahnya ketahanan fisik (physical weakness) karena rendahnya konsumsi pangan baik kualitas maupun kuantitas sehingga konsumsi gizi mereka sangat rendah yang berakibat pada rendahnya produktivitas mereka.

(5) Masalah keterisolasian (isolation), keterisolasian fisik tercermin dari kantong-kantong kemiskinan yang sulit dijangkau, sedangkan keterisolasian sosial tercermin dari ketertutupan dalam integrasi masyarakat miskin dengan masyarakat yang lebih luas.

Sedangkan menurut Kuncoro bahwa dari sisi ekonomi, kemiskinan itu terjadi karena disebabkan tiga hal, antara lain: adanya ketidaksamaan pola kepemilikan sumber daya yang menimbulkan distribusi pendapatan timpang, perbedaan kualitas sumber daya manusia, kualitas sumber daya manusia yang rendah menunjukkan produktivitas rendah, upah rendah dan perbedaan akses dan modal. Ketiga penyebab kemiskinan 
tersebut di atas bermuara pada teori lingkaran setan kemiskinan (vicious circle of poverty).

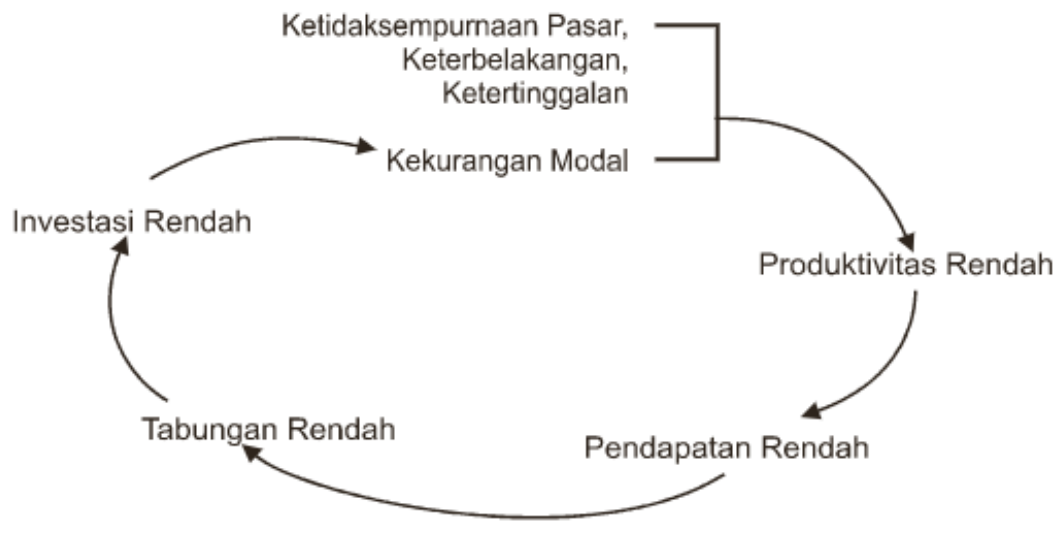

Adanya keterbelakangan, ketertinggalan, ketidaksempurnaan pasar, kurangnya modal menyebabkan rendahnya produktivitas. Rendahnya produktivitas mengakibatkan rendahnya pendapatan yang mereka terima. Rendahnya pendapatan akan berimplikasi pada rendahnya tabungan dan investasi, rendahnya investasi akan berakibat pada keterbelakangan dan seterusnya. Logika berpikir yang dikemukakan Nurkse yang dikutip Kuncoro, mengemukakan bahwa negara miskin itu miskin karena dia miskin (a poor country is poor because it is poor). ${ }^{7}$

D. Langkah-Langkah Dalam Mengentaskan Kemiskinan

Al-Qardhawi mengemukakan pandangannya tentang upaya pengentasan kemiskinan melalui enam solusi; pertama, setiap orang Islam harus bekerja keras dan meningkatkan etos kerja; kedua, orang-orang kaya menyantuni dan menjamin kehidupan ekonomi keluarga dekatnya yang miskin; ketiga, meningkatkan dan mengintensifkan pelaksanaan zakat secara profesional; keempat, mengintensifkan pengumpulan bantuan dari sumber, baik dari swadaya masyarakat maupun pemerintah; kelima, mendorong orang-orang kaya untuk mengeluarkan sadakah tathawwu' kepada orang-orang yang sangat membutuhkannya; keenam, bantuan bantuan sukarela dan kebaikan hati secara individual dan insidental.

Keenam solusi itu disimpulkannya menjadi tiga tahapan, yaitu : tahap pertama, secara khusus harus diupayakan oleh pihak fakir miskin itu sendiri dengan

\footnotetext{
${ }^{7}$ Irsyad Andriyanto, "STRATEGI PENGELOLAAN ZAKAT DALAM PENGENTASAN KEMISKINAN" 19 (2011): $28-30$.
} 
meningkatkan kerja selama ia masih memiliki kemampuan dan kesanggupan berusaha. Dalam hal ini masyarakat dan pemerintah mendorong dan menstimulus dalam bentuk modal atau peralatan untuk berusaha sehingga mereka mampu mandiri; tahap kedua, masyarakat muslim meningkatkan kepedulian sosial dan bantuan riil secara rutin diluar kewajiban zakat, terutama dari pihak keluarga dekat para fakir miskin itu sendiri; tahap ketiga, secara khusus, pemerintah mencurahkan perhatian dan political will-nya, karena secara syariat pemerintahan Islam berkewajiban untuk menjamin kebutuhan pokok hidup rakyat, terutama bagi fakir miskin yang tidak memiliki mata pencaharian atau keluarga dekat dan orang yang menjaminnya. Kewajiban pemerintah ini tidak hanya terhadap orang Islam saja, tetapi termasuk pula kafir dzimmi yang berada dalam perlindungan pemerintahan Islam. Persoalan pokok dalam pengentasan kemiskinan dan upaya-upaya menjembatani jurang antara kelompok kaya dengan golongan miskin, adalah meningkatkan pemberdayaan zakat dengan terlebih dahulu memantapkan pemahaman tentang konsep teoritik dan operasionalnya sebagai motivasi dalam upaya meningkatkan pelaksanaan dan pengamalan zakat. Pengentasan kemiskinan melalui proses yang panjang dapat ditempuh dua langkah dan pendekatan yakni: pendekatan parsial dan pendekatan struktural. Pendekatan parsial, yaitu dengan pemberian bantuan langsung berupa sadakah biasa dari orang-orang kaya dan dari dana zakat betul-betul tidak produktif lagi (karena cacat jasmani dan rohani). Pendekatan struktural, model pendekatan ini bertujuan untuk menuntaskan kemiskinan secara sistematis, dengan cara menghilangkan faktor-faktor penyebab kemiskinan itu sendiri, baik yang disebabkan oleh faktor internal maupun eksternal. ${ }^{8}$

\section{Kesimpulan}

Berdasarkan dari penguraian diatas dapat disimpulkan bahwa :

Zakat dalam istilah fiqih berarti sejumlah harta tertentu yang diwajibkan Allah SWT diserahkan kepada orang-orang yang berhak

Dan adapun tujuaanya dapat dilihat dari berbagai aspek, antara lain adalah dari aspek ibadah, sosial, dan ekonomi.

1. Tujuan zakat dalam aspek ibadah adalah suatu bentuk penghambaan seorang insan kepada Allah selaku Pencipta, Pemilik, \& Pengatur alam semesta beserta isinya melalui pengorbanan harta.

\footnotetext{
${ }^{8}$ Trisno, A.syathir, “Maqasid Zakat Dalam Mengentaskan Kemiskinan," 363-64.
} 
2. Tujuan zakat dalam aspek sosial adalah menjadi media distribusi kekayaan antara orang-orang yang berkelebihan harta dengan orang-orang yang kekurangan harta.

3. Tujuan zakat dalam aspek ekonomi adalah media sirkulasi kekayaan agar harta tidak berputar di kalangan orang-orang kaya saja.

Sedangkan Kemiskinan juga berarti keadaan melarat atau keadaan miskin. Orang miskin adalah orang yang memiliki harta dan memiliki pekerjaan halal yang sesuai dengannya yang bisa menutupi kebutuhannya dan orang yang berada di bawah tanggung jawabnya, namun sebenarnya tidak mencukupi secara Ideal.

Dan upaya pengentasan kemiskinan dapat dilakukan melalui enam solusi; pertama, setiap orang Islam harus bekerja keras dan meningkatkan etos kerja; kedua, orang-orang kaya menyantuni dan menjamin kehidupan ekonomi keluarga dekatnya yang miskin; ketiga, meningkatkan dan mengintensifkan pelaksanaan zakat secara profesional; keempat, mengintensifkan pengumpulan bantuan dari sumber, baik dari swadaya masyarakat maupun pemerintah; kelima, mendorong orang-orang kaya untuk mengeluarkan sadakah tathawwu' kepada orang-orang yang sangat membutuhkannya; keenam, bantuan bantuan sukarela dan kebaikan hati secara individual dan insidental.

\section{Referensi}

Abdullah, RIdwan Triandi, Dadang Kuswana, and Yuliani Yuliani. "Pola Pengelolaan Manajemen Zakat BAZ Kota Bandung Dalam Mengatasi Kemiskinan.” Tadbir: Jurnal Manajemen Dakwah 1, no. 4 (2016): 355-72. https://doi.org/10.15575/tadbir.v1i4.145.

Andriyanto, Irsyad. "STRATEGI PENGELOLAAN ZAKAT DALAM PENGENTASAN KEMISKINAN” 19 (2011): 28-30.

Samsul. "TUJUAN DAN SASARAN ZAKAT DALAM KONTEKS IBADAH DAN MUAMALAH.” IBEF 1 (2020): 85-86.

Trisno, A.syathir, Abd.wahid. "Maqasid Zakat Dalam Mengentaskan Kemiskinan.” Tasamuh;Studi Islam 12 (2020): 359. 